\title{
Characterization of Nanocrystalline Yttria-Stabilized Zirconia: An In Situ HTXRD Study
}

\author{
Mridula Biswas, ${ }^{1}$ Chandrashekhar S. Kumbhar, ${ }^{2}$ and D. S. Gowtam ${ }^{3}$ \\ ${ }^{1}$ Naval Materials Research Laboratory, Ambernath, India \\ ${ }^{2}$ Ceramic Division, Naval Materials Research Laboratory, Ambernath, India \\ ${ }^{3}$ Department of Marine Materials, Naval Materials Research Laboratory, Ambernath, India
}

Correspondence should be addressed to Mridula Biswas, luckymridula@gmail.com

Received 17 February 2011; Accepted 20 March 2011

Academic Editors: P. O. Käll, I. Škorvánek, and V. Valtchev

Copyright (c) 2011 Mridula Biswas et al. This is an open access article distributed under the Creative Commons Attribution License, which permits unrestricted use, distribution, and reproduction in any medium, provided the original work is properly cited.

Nanocrystalline yttria-stabilized zirconia powders, synthesized by the citrate nitrate gel combustion route, with yttria concentration varying from 8 to $12 \mathrm{~mol} \%$ were studied by in situ high temperature X-ray diffraction in the temperature range of $25-1000^{\circ} \mathrm{C}$. The sample obtained has a high specific surface area of $35 \mathrm{~m}^{2} / \mathrm{g}$ while calculated surface area was around $123 \mathrm{~m}^{2} / \mathrm{g}$. The in situ high temperature X-ray diffraction study revealed that crystallite size remains in the range of 7-9 nm up to $800^{\circ} \mathrm{C}$ and then rapidly grows up to $21-23 \mathrm{~nm}$ upto $1000^{\circ} \mathrm{C}$; only holding the material at $1000^{\circ} \mathrm{C}$ for 30 minutes can promote grain growth in the range of $42-49 \mathrm{~nm}$. Coefficient of thermal expansion ranges from 9.65 to $9.03 \mathrm{ppm} /{ }^{\circ} \mathrm{C}$ for $8-12 \mathrm{~mol} \%$ nanocrystalline yttria-stabilized zirconia.

\section{Introduction}

Solid oxide fuel cell (SOFC) is a solid state fuel cell, without the presence of any liquid, operating at approximately 800 $1000^{\circ} \mathrm{C}$. In addition to the advantages of fuel cells, the high operating temperature renders several other benefits for SOFC, such as a simple gas supply system without any requirement for external reformer, generation of high quality heat which can be utilized for other purposes, use of a wide variety of fuels, and rapid reaction kinetics [1]. Therefore the SOFC is considered to be the best environment friendly distributed power sources in the foreseeable future.

The fuel cell consists of a dense oxide ion-conducting electrolyte and two porous electrodes. Yttria-stabilized zirconia (YSZ) is most commonly used as the electrolyte in the SOFC because of its high ionic conductivity and desirable chemical stability in both oxidizing and reducing atmospheres. The other common materials are nickel/YSZ cermet for the anode, substituted lanthanum manganite for the cathode, and substituted lanthanum chromite for the interconnect material due to their chemical stability, electronic conductivity, and electrochemical properties [2]. Also, ferritic steels have been used as a low-cost and well-workable interconnect material [3].

As all SOFC components are solid, mismatches of coefficients of thermal expansion (CTEs) between the materials can become a serious problem during fabrication or at thermal cycles during operation. The high operating temperature causes severe problem to the materials due to the microstructural change of each cell component, solid state reaction between the electrolyte and electrodes and thermal cycling. It is essential for SOFC stack that an electrolyte must have the almost same coefficient of thermal expansion (CTE) as those of electrodes over the whole temperature range of operation. Especially in the case of anode supported SOFCs [4], the difference in CTE between electrolyte and anode substrate leads to significant thermoelastic bending of the cells $[5,6]$ causing cell fracture in stack assembling in the worst case. In order to reduce the bending and to make planar SOFCs a reliable technology, the CTE of the YSZ electrolyte has to be tailored. Therefore, measuring the intrinsic CTE value of YSZ materials is important.

In this research work, in situ high-temperature X-ray diffraction was carried out to study the CTE and crystallite 
growth behavior with temperature and time. Crystallite size change has been studied in view of possible change in microstructure of electrolyte during operation.

\section{Materials and Method}

Zirconium oxychloride octahydrate, $\mathrm{ZrOCl}_{2} \cdot 8 \mathrm{H}_{2} \mathrm{O}(99 \%$, Indian Rare Earth Ltd., Mumbai, India), Yttria, $\mathrm{Y}_{2} \mathrm{O}_{3}$ (99.9\%, Indian Rare Earth Ltd.), citric acid (Central Drug House (P) Ltd., New Delhi, India), and nitric acid (Merck, Mumbai, India) used were of analytical reagent grade. $8-12 \mathrm{~mol} \%$ YSZ materials were prepared by citric acid combustion route. The procedure of the citric acid combustion route has already been reported [7]. The powder obtained after calcination was deagglomerated using isopropanol as solvent in a planetary ball mill using zirconia grinding media for 24 hours. X-ray diffractometry was carried out for the purposes of phase identification, determination of precise lattice parameter, X-ray density, crystallite size, coefficient of thermal expansion (CTE), and rate of grain growth with temperature and time. The powders were characterized by high temperature X-ray diffractometer (special attachment no. HTK 1200, Anton Paar, Austria, Europe) of XPert, MPD, PAnalytical B.V., Almelo, The Netherlands. $\mathrm{Cu}$ target was used for diffraction by $\mathrm{CuK} \alpha$ radiation. $K_{\beta}$ radiation was eliminated by nickel filter. The powder samples were placed on the spinner attachment to get reasonable randomness. The measurement was carried out in the angular region of $2 \theta=20-80^{\circ}$ with a step size of $0.005^{\circ}$ in the temperature range of $25-1000^{\circ} \mathrm{C}$. The temperature was raised at a rate of $10^{\circ} \mathrm{C}$ per minute, and the scan rate was kept $0.00021^{\circ}$. The raw X-ray diffraction (XRD) data was processed by removing $K \alpha_{2}$. The XRD data were suitably processed for background reduction and smoothening using fast Fourier method. This method involves measurement of lattice parameter of solid solution or compounds as a function of temperature. Lattice parameter of the material varies with the concentration of the component materials. Any change in concentration of component materials or temperature produces a significant change in lattice parameter. This change can be detected by high temperature XRD (HTXRD), but the precise measurement is necessary to have the accurate measurement of lattice parameter [8]. In this context, lattice parameter has been determined using the following [8]:

$$
a=a_{o}+a_{o} K \cos ^{2} \theta,
$$

where $a_{o}, K$, and $a$ are the true lattice parameter, constant and calculated lattice parameter, respectively. The value of a computed for each line on the pattern has been plotted against $\cos ^{2} \theta$, a straight line was obtained, and $a_{o}$ was found by extrapolating this line to $\cos ^{2} \theta=0$. The lattice parameter was measured at various temperatures like 25, 100, 200, 300, $400,500,600,700,800,900$, and $1000^{\circ} \mathrm{C}$. CTE $(\alpha)$ has been measured using the following:

$$
\alpha=\frac{\mathrm{lp}_{2}-1 \mathrm{p}_{1}}{\left(t_{2}-t_{1}\right) * \mathrm{lp}_{1}},
$$

where $l p_{1}$ and $l p_{2}$ are the lattice parameter at temperatures $t_{2}$ and $t_{1}$, respectively.
The pattern of grain growth with increase in temperature and time was studied by change in crystallite size. The crystallite sizes at various temperatures were determined using Scherrer relation, $D=0.94 \lambda / \beta \cos \theta$, where $D$ is the crystallite size, $\lambda$ is the wavelength of $\mathrm{Cu} K \alpha$ radiation ( $1.5406 \AA$ ), $\lambda$ is full width at half maxima (FWHM) of the broadening of the diffraction line, and $\theta$ is half the angle of diffraction. Instrumental broadening was eliminated from the raw XRD data using the following:

$$
\beta=\sqrt{\left(\beta_{m}^{2}-\beta_{s}^{2}\right)}
$$

where $\beta_{s}$ is the system broadening which was found using a polycrystalline silicon standard sample, and $\beta_{m}$ is the observed broadening in the XRD raw data of the YSZ sample [8].

The specific surface area (SSA) of the powders was measured by Brunauer-Emmett-Teller (BET) method (Sorptomatic 1990, Thermo Fennigan, Rodano (MI), Italy) by determining the amount of nitrogen gas absorbed as a monomolecular layer on the sample. SSA was also calculated from the crystallite size obtained from Scherrer equation using XRD data, assuming the presence of spherical particles. SSA was measured using the following [9]:

$$
\text { SSA }=\frac{1000 * 6}{\text { crystallite size } * \text { density }} .
$$

\section{Result and Discussion}

The materials under study in this research work had been cubic in structure and were randomly oriented. Therefore, linear coefficient of thermal expansion is sufficient to explain their three-dimensional coefficient of thermal coefficient. Normal practice among the researchers is to adopt the dilatometry method for determination of CTE using sintered samples. However, dilatometry of the sintered samples does not preclude the effects of the porosity and their shape, size, and distribution pattern and their contribution towards achieving the true CTE. It often makes difficult to find the accurate CTE of the materials due to the said extrinsic parameters. In this research programme, emphasis was given to find out the true and intrinsic CTE of YSZs by adopting high temperature X-ray diffractometry and analyzing the expansion of respective lattice parameters. This method is intrinsic in nature and excludes the effects of variants of porosities, and so forth. Figure 1 gives the multiple plots of the high temperature powder XRD profiles of the sample scanned between room temperature $\left(25^{\circ} \mathrm{C}\right)$ and $1000^{\circ} \mathrm{C}$. The HTXRD profiles were subjected to correction described in experimental to obtain information about the change in the crystallite size and lattice parameters of the sample as a function of temperature. Figure 2 shows the pattern of the increase in lattice parameter, " $a$," with respect to the systematic temperature variation from room temperature of $25^{\circ} \mathrm{C}$ to $1000^{\circ} \mathrm{C}$. Linear increase in lattice parameter, " $a$," is observed in Figure 2. The plot shows a linear increase in the value of the lattice parameter " $a$." Hence an increase in the unit cell volume as a function of temperature can be 
TABLE 1: Coefficient of thermal expansion with respect to temperature.

\begin{tabular}{lccccc}
\hline Temperature $\left({ }^{\circ} \mathrm{C}\right)$ & $8 \mathrm{YSZ}\left(\mathrm{ppm} /{ }^{\circ} \mathrm{C}\right)$ & $9 \mathrm{YSZ}\left(\mathrm{ppm} /{ }^{\circ} \mathrm{C}\right)$ & $10 \mathrm{YSZ}\left(\mathrm{ppm} /{ }^{\circ} \mathrm{C}\right)$ & $11 \mathrm{YSZ}\left(\mathrm{ppm} /{ }^{\circ} \mathrm{C}\right)$ & $12 \mathrm{YSZ}\left(\mathrm{ppm} /{ }^{\circ} \mathrm{C}\right)$ \\
\hline 100 & 9.05 & 8.61 & 8.41 & 8.11 & 7.78 \\
200 & 9.01 & 8.48 & 8.1 & 7.82 & 8.03 \\
300 & 9.2 & 8.48 & 8.26 & 8.03 & 8.09 \\
400 & 8.95 & 8.57 & 8.28 & 8.14 & 8.12 \\
500 & 9.04 & 8.83 & 8.73 & 8.34 & 8.13 \\
600 & 9.35 & 8.87 & 8.8 & 8.47 & 8.19 \\
700 & 9.37 & 9.08 & 8.8 & 8.92 & 8.17 \\
800 & 9.38 & 9.19 & 9.07 & 9.21 & 9.03 \\
900 & 9.45 & 9.22 & 9.35 & & 9.26 \\
1000 & 9.65 & 9.45 & & & \\
\hline
\end{tabular}

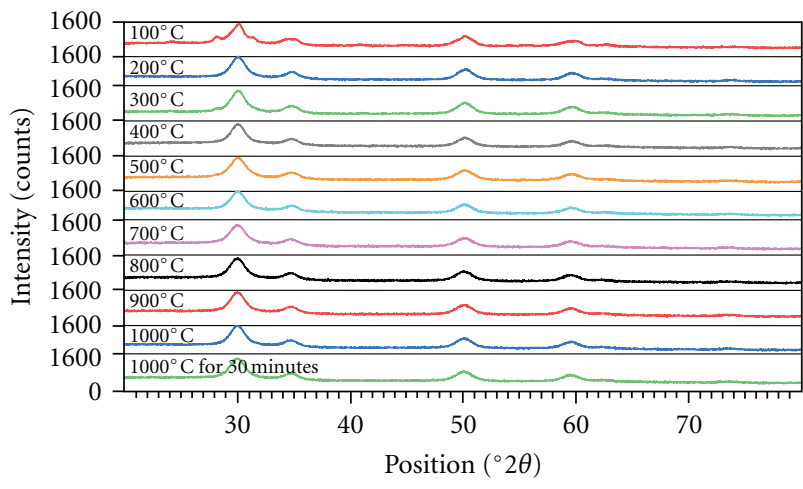

FIGURE 1: XRD plots of 8 YSZ at different temperature.

observed. The reason behind this is the continuous increase in lattice parameter with increase in temperature. The CTE values are given in Table 1. From the values given in Table 1, it is observed that CTE is increasing with temperature and decreasing with increase in yttria concentration in zirconia.

This observation is in good agreement with those by Tsukuma et al. [10], Yasuda and Hishinuma [11], and Hayashi et al. [12]. But the present work shows that CTEs of YSZ compounds differ from those obtained by them. This difference may be due to the different procedures adopted by different authors. The above-mentioned authors used dilatometer to obtain CTEs for YSZs, while high temperature XRD has been used for the same purpose in the present investigation. An increasing trend in CTE of a solid solution is observed as the solute concentration of the solid solution increases, depending on the condition that lattice parameters of the solute are larger than those of the solvent [11]. But yttria-stabilized zirconia does not follow this trend. Tsukuma et al. explained this diversified observation by pair correlation function of ions using molecular dynamics simulation [10]. The yttrium-oxygen (Y-O) and zirconium-oxygen ( $\mathrm{Zr}$ $\mathrm{O})$ distances obtained from pair correlation function are 0.23 and $0.21 \mathrm{~nm}$, respectively, when they are not in combination with each other. But the distances between cations and anion were observed to decrease when they were combined as a compound. The decrease of the distances increases the binding energy of the ions. This higher binding energy

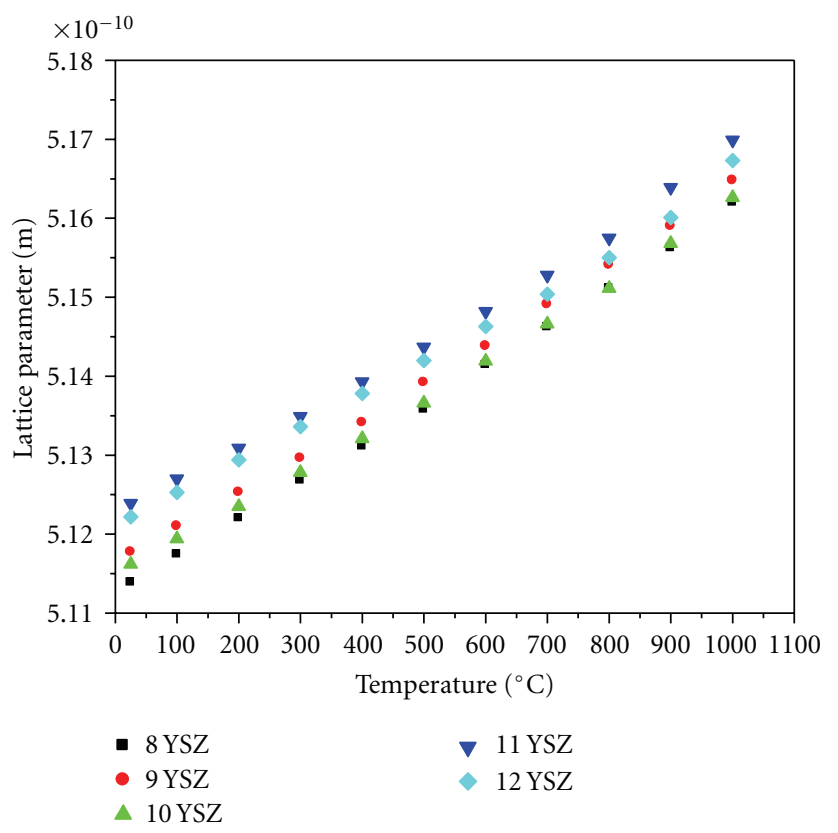

Figure 2: Variation of lattice parameter with respect to temperature.

resists the separation of the ions from one another. As a consequence, decrease in coefficient of thermal expansion of YSZ is observed as the yttria content is increased [10].

Figure 3 shows the variation of crystallite size with temperature. It is well established that heat treatment has a pronounced effect on crystallites. It is also widely reported that normally the crystallites grow at elevated temperatures at which solid state diffusion is significant. Crystallite sizes are primarily dependent on temperature and the soaking period at that temperature. High temperature XRD was carried out on the phase pure powders obtained by the combustion reaction followed by heat treatment at $550^{\circ} \mathrm{C}$. Crystallite sizes were calculated from the refined high temperature XRD plots using Scherrer formula. It is observed that nearly up to $800^{\circ} \mathrm{C}$ the change in crystallite sizes remained insignificant. Lack of adequate activation energy for solid state diffusion required for crystallite growth had been the primary reason. Beyond 


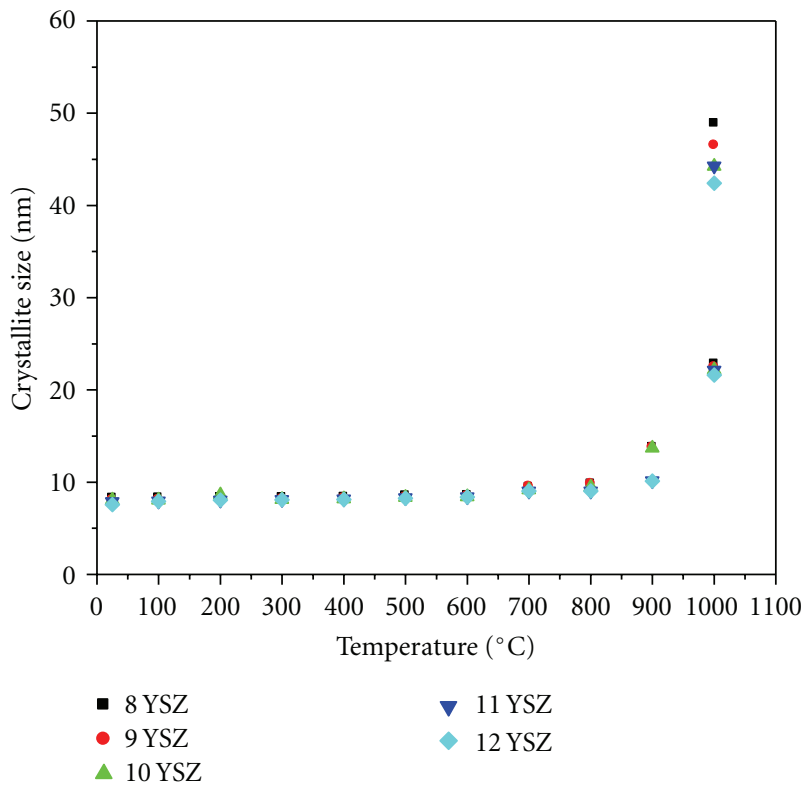

Figure 3: Variation of crystallite size with respect to temperature.

$800^{\circ} \mathrm{C}$, there had been exponential growth in crystallite size as can be seen in the plot. This signifies that about $800^{\circ} \mathrm{C}$ and beyond the activation energy is sufficient enough for solid state diffusion for promotion of rapid growth of crystallite sizes of the YSZ samples. In this experiment, a systematic heating schedule was maintained from room temperature to $1000^{\circ} \mathrm{C}$. However, at the end point of the temperature, in this case at $1000^{\circ} \mathrm{C}$, a soaking period was provided for thirty minutes to study the effect of soaking period at a temperature. It is observed that there had been pronounced effect of soaking period on the growth of crystallite size.

The sample has a BET surface area of the sample $\left(35 \mathrm{~m}^{2} / \mathrm{g}\right.$ ) obtained by the nitrogen adsorption experiment. The BET surface area is not comparable to the specific surface area $\left(123 \mathrm{~m}^{2} / \mathrm{g}\right)$ calculated from the crystallite size. Therefore, it can be concluded that the YSZ nanopowders are agglomerated.

\section{Conclusion}

Intrinsic coefficient of thermal expansions observed range from 9.65 to $9.03 \mathrm{ppm} /{ }^{\circ} \mathrm{C}$ in the temperature range of $25-1000^{\circ} \mathrm{C}$. Effect of temperature on crystallite size was observed. There had been exponential growth in crystallite size beyond this temperature. Nearly up to $800^{\circ} \mathrm{C}$, size of crystallite does not show any significant change with increase in temperature, and beyond $800^{\circ} \mathrm{C}$ abrupt change occurs. The adequate activation energy for promoting ions from one side of the crystallite boundary to the other side is obtained at temperatures higher than $800^{\circ} \mathrm{C}$.

\section{Acknowledgments}

The authors are thankful to Dr. J. N. Das, Director, Dr. S. C. Sharma, Associate Director, and N. M. Gokhale,
HOD, Ceramic Division, NMRL, Ambernath, India for their encouragement and support.

\section{References}

[1] B. C. H. Steele and A. Heinzel, "Materials for fuel-cell technologies," Nature, vol. 414, no. 6861, pp. 345-352, 2001.

[2] N. Q. Minh, "Ceramic fuel cells," Journal of the American Ceramic Society, vol. 76, no. 3, pp. 563-588, 1993.

[3] J. P. Abellan, V. Shemet, F. Tietz, L. Singheiser, W. J. Quadakkers, and A. Gil, "Ferritic steel interconnect for reduced temperature SOFC," in Proceedings of the 7th International Symposium Solid Oxide Fuel Cells, H. Yokokawa and S. C. Singhal, Eds., pp. 811-819, The Electrochemical Society, Pennington, NJ, USA, 2001.

[4] H.P. Buchkremer, U. Diekmann, and D. Stöver, "Component manufacturing and stack integration of anode supported planar SOFC system," in Proceedings of the 2nd European Solid Oxide Fuel Cell Forum, B. Thorstensen, Ed., pp. 221-228, Oberrohrdorf, Switzerland, 1996.

[5] F. Meschke and R. W. Steinbrech, "In situ observation of assembling processes in SOFC stacks," in Proceedings of the 6th European Solid Oxide Fuel Cell Forum, M. Dokiya and S. C. Singhal, Eds., pp. 1047-1056, The Electrochemical Society, Pennington, NJ, USA, 1999.

[6] R. Vassen, R. W. Steinbrech, F. Tietz, and D. Stöver, "Modelling of stresses and bending behaviour during co-firing of anodeelectrolyte componentes," in Proceedings of the 3rd European Solid Oxide Fuel Cell Forum, P. Stevens, Ed., p. 557, Oberrohrdorf, Switzerland, 1998.

[7] M. Biswas, K. Shashidhara, P. K. Ojha, T. K. Chongdar, and N. R. Bandyopadhyay, "Linear combination of atomic orbitals approximation in nanocrystalline yittria-stabilized zirconia synthesized by citrate-nitrate gel combustion process," Journal of the American Ceramic Society, vol. 91, no. 3, pp. 934-937, 2008.

[8] B. D. Culity, Elements of X-Ray Diffraction, Addison-Wesley, Reading, Mass, USA, 1978.

[9] M. Bhagwat and V. Ramaswamy, "Synthesis of nanocrystalline zirconia by amorphous citrate route: structural and thermal (HTXRD) studies," Materials Research Bulletin, vol. 39, no. 11, pp. 1627-1640, 2004.

[10] K. Tsukuma, Y. Kubota, and K. Nobugai, "Thermal and mechanical properties of $\mathrm{Y}_{2} \mathrm{O}_{3}$ partially stabilized zirconia," Journal of the Ceramic Society of Japan, vol. 92, no. 5, pp. 233241, 1984.

[11] I. Yasuda and M. Hishinuma, "Lattice expansion of acceptordoped lanthanum chromites under high-temperature reducing atmospheres," Electrochemistry, vol. 68, no. 6, pp. 526-530, 2000.

[12] H. Hayashi, T. Saitou, N. Maruyama, H. Inaba, K. Kawamura, and M. Mori, "Thermal expansion coefficient of yttria stabilized zirconia for various yttria contents," Solid State Ionics, vol. 176, no. 5-6, pp. 613-619, 2005. 

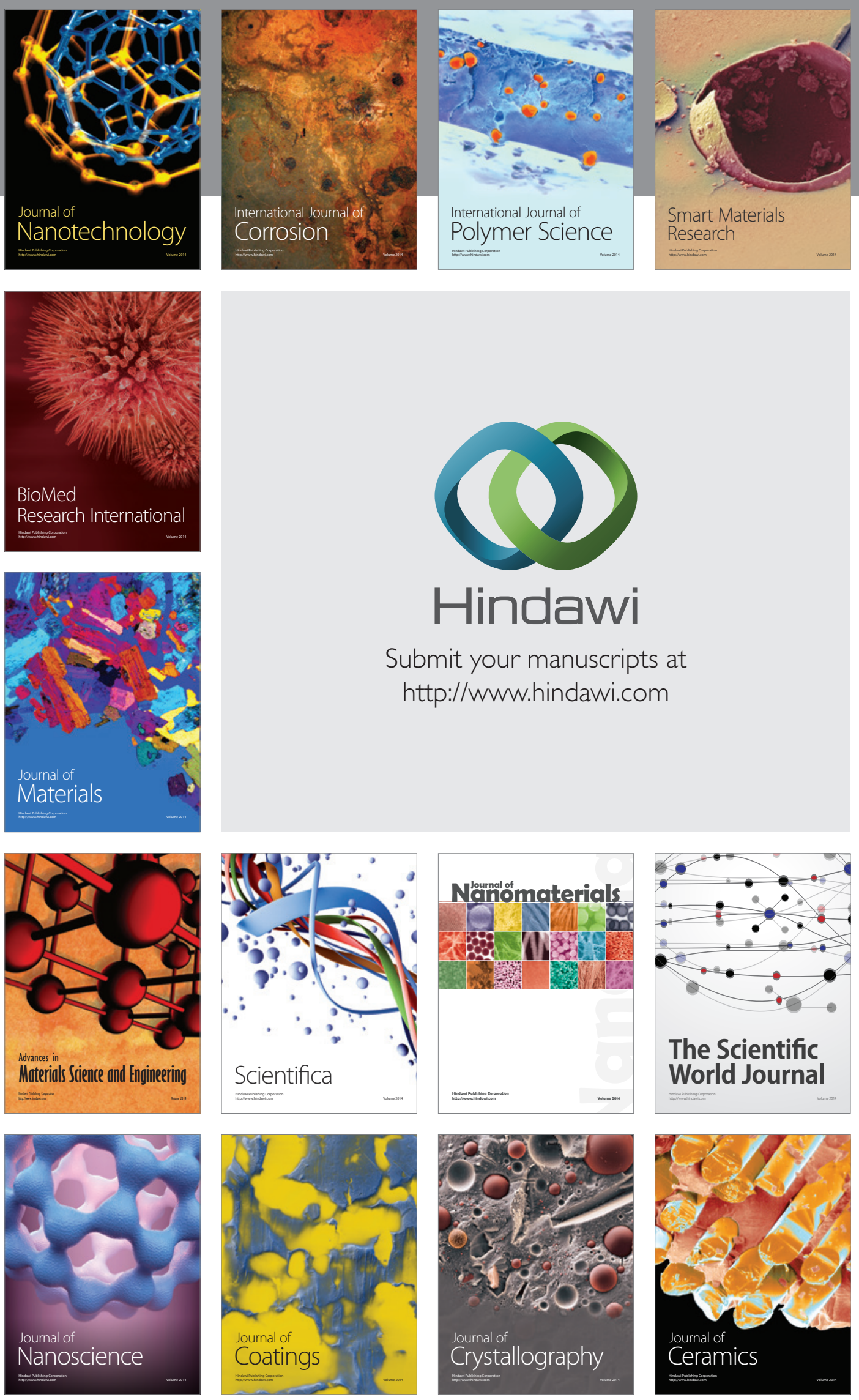

The Scientific World Journal

Submit your manuscripts at

http://www.hindawi.com

\section{World Journal}

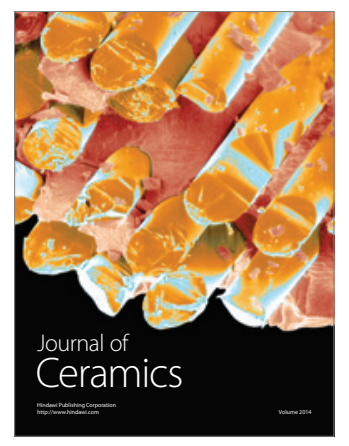

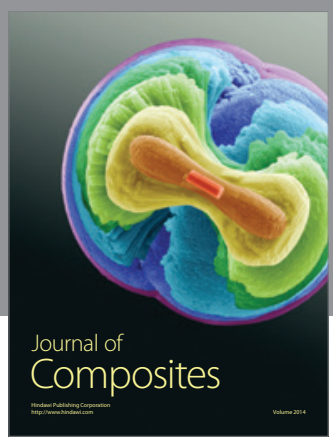
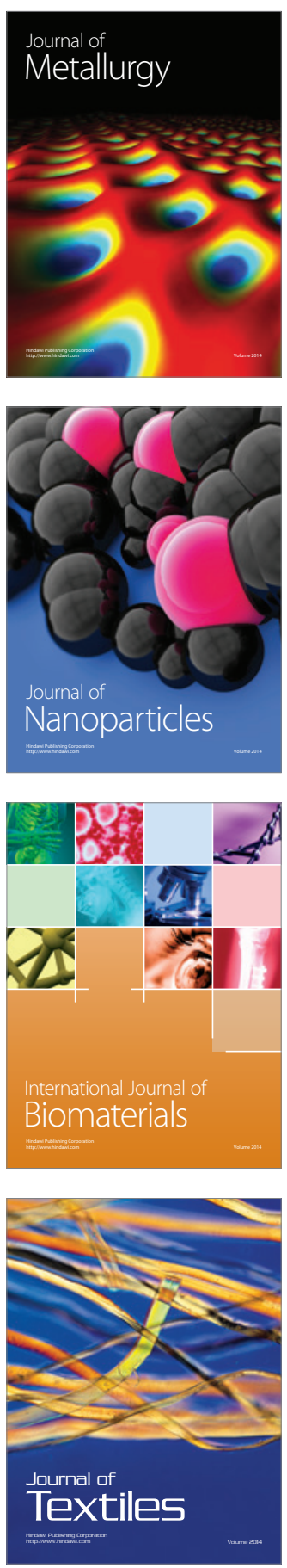